\title{
Girondins jusqu'au tombeau. Une révolte bordelaise dans la Révolution
}

\section{Bernard Vinot}

\section{(2) OpenEdition \\ 1 Journals}

Édition électronique

URL : https://journals.openedition.org/ahrf/2155

DOI : 10.4000/ahrf.2155

ISSN : 1952-403X

\section{Éditeur :}

Armand Colin, Société des études robespierristes

\section{Édition imprimée}

Date de publication : 1 mars 2005

Pagination : 169-170

ISSN : 0003-4436

\section{Référence électronique}

Bernard Vinot, « Girondins jusqu'au tombeau. Une révolte bordelaise dans la Révolution », Annales historiques de la Révolution française [En ligne], 339 | janvier-mars 2005, mis en ligne le 24 avril 2006, consulté le 23 avril 2022. URL : http://journals.openedition.org/ahrf/2155 ; DOI : https://doi.org/ 10.4000/ahrf.2155

Ce document a été généré automatiquement le 23 avril 2022.

Tous droits réservés 


\title{
Girondins jusqu'au tombeau. Une révolte bordelaise dans la Révolution
}

\author{
Bernard Vinot
}

\section{RÉFÉRENCE}

Anne de Mathan, Girondins jusqu'au tombeau. Une révolte bordelaise dans la Révolution, Bordeaux, Éditions du Sud-Ouest, 2004, 317 p., ISBN 9782879015439

1 Ce livre, comme son titre ne l'indique pas, est une prosopographie de ceux que l'auteur appelle les « Girondistes », partisans locaux des Girondins entrés en rébellion à la suite des événements du 31 mai-2 juin 1793 et jusque-là négligés par la recherche. Il est issu d'une thèse de doctorat soutenue à l'Université Bordeaux III en janvier 2000, nourrie des archives de la Terreur, de celles de la "commission populaire » bordelaise et de toutes les sources départementales se rapportant à ce moment dramatique. L'étude s'articule en trois parties: les hommes de la Gironde, l'idéologie girondine, la commission populaire de salut public à l'œuvre.

2 La première partie, très intéressante, définit un corpus de 551 acteurs engagés à des titres divers, comprenant un noyau dur de 115 personnes, fondateurs et animateurs de la «commission populaire de salut public», organe de la révolte, 241 relais actifs (courtiers, volontaires de la force armée, administrateurs, sectionnaires), enfin une nébuleuse de parents, amis, sympathisants et signataires avérés. Nés pour les deux tiers dans le département de la Gironde, d'âges assez avancés, ce sont des hommes (seulement huit femmes) bien intégrés dans le milieu de la bourgeoisie urbaine, négociants, hommes de loi, artisans et leurs commis. Une analyse des contributions et des fortunes révèle qu'ils paraissent plus fortunés que la moyenne de leurs concitoyens, avec même pour certains des niveaux de vie brillants. L'observation des sociabilités est édifiante. Les protestants représentant 1,5\% de la population constituent $7 \%$ du corpus, 
et les juifs ( $1,8 \%$ pour $1,8 \%$ de la population) sont issus des milieux les plus assimilés aux élites locales. La participation maçonne dans la direction de l'insurrection et de sa branche armée, dans les vecteurs de propagation à l'intérieur du département, est la plus forte (soixante-deux) et la plus déterminée. Son influence n'est dépassée que par celle de la Société des Amis de la liberté et de l'égalité, affiliée aux Jacobins de Paris, qui regroupe au moins la moitié des Girondistes. Ont aussi leur part dans ces engagements les réseaux de relations qui unissent députés et commettants, négociants associés, patrons et commis. Tous ces hommes manifestent un commun attachement à la Révolution, ont accepté la mort du roi, participent à l'effort de guerre - en armant des corsaires -, aux carrières publiques, aux dons patriotiques et aux achats de biens nationaux. Bref, en 1793, ils se comportent en révolutionnaires convaincus et avancés.

3 L'idéologie girondiste s'affirme à travers quatre-vingt-dix-sept textes officiels sans réserver de grande surprise dans la mesure où les conceptions affirmées paraissent calquées sur celles de leurs députés. À la suite du coup de force des 31 mai- 2 juin, ils expriment un « légalisme outragé », fustigent la destruction de la liberté, l'« anarchie » et réclament une constitution. La défiance envers Paris s'accompagne d'un «fier départementalisme ", mais le fédéralisme dont on les accuse n'a pas, du moins stricto sensu, de «fondement réel ». À la lumière de leurs déclarations, les Girondistes sont définis comme des libéraux conservateurs, méfiants à l'égard des aspirations égalitaires des sans-culottes, attachés à la liberté du commerce, au respect des propriétés et aux principes de 89. Ils aspireraient en outre au bonheur, à des valeurs traditionnelles comme l'honneur, la sagesse et les bonnes mœurs. C'est dans l'insurrection que se serait forgée cette identité girondine profondément antinomique, selon l'auteur, de celle des Montagnards, lesquels placent la nation avant l'individu et le salut de la République avant les droits de l'homme.

4 La commission populaire de salut public est en réalité l'apanage de l'élite minoritaire qui constitue la partie politisée de la population, soit un cinquième des habitants de Bordeaux et $28 \%$ de celle des communes du département. Elle ne reconnaît pas le tribunal révolutionnaire, organise une armée de volontaires financée par un emprunt d'un million sur les citoyens fortunés, décide la liberté du commerce des grains et dépêche dix-huit «missionnaires de la liberté » pour entraîner les départements dans son sillage sans pour autant faire alliance avec les révoltes royalistes. Mais la Convention la désarçonne en soumettant une constitution à l'approbation publique. Très vite aux abois, la commission peine à nourrir le peuple en mission, s'empare des fonds de l'hôtel des monnaies, laisse molester par la rue les représentants du peuple, ne parvient pas à lever la force militaire au sein d'une population indifférente et peu encline à aller « jusqu'au tombeau ».

5 Cette recherche définit avec précision la genèse, l'importance, la portée et les limites vite atteintes de ce mouvement. On peut ne pas partager certaines appréciations, préférences et interprétations de l'auteur, surtout dans la deuxième partie trop théorique et, pour nous, la moins féconde. La méthode historique retenue pour définir l'idéologie girondiste à la lumière de discours publics, déclarations, proclamations, etc., s'accompagne d'une analyse trop mollement critique, même si la dernière partie, très factuelle, vient ensuite s'inscrire en correction. L'opposition Girondins-Montagnards, définis, pour les premiers, à travers une littérature de combat et, pour les seconds, à partir d'une politique de circonstance fondée sur une alliance réticente et momentanée avec les sans-culottes parisiens, paraît exagérée. Plus jeunes, plus déterminés mais 
formés dans le même moule, ces hommes-ci ne sont pas si différents de ceux-là en dehors d'un moment politique dramatique. Robespierre est-il hostile au respect des propriétés, au bonheur, à l'honneur, à la sagesse, aux bonnes mœurs ? Les conceptions économiques profondes d'un Saint-Just (voir M. Abensour : Saint-Just, Euvres complètes, pp.786-797), pour ne citer qu'un exemple précis, sont-elles si éloignées de celles qui sont prônées sur les bords de la Garonne?

Paradoxalement, ce beau travail d'Anne de Mathan contribue à réhabiliter la théorie des circonstances traitée avec trop de désinvolture par les modes du temps car, le livre fermé, s'impose à l'esprit un parallèle, mutatis mutandis, entre la politique du Comité de salut public et celle de la commission populaire de salut public. En quelques semaines d'existence en effet, et au mépris de principes proclamés, celle-ci entre en insurrection, se fait complice de violence à l'égard des représentants du peuple, se dote d'un « arsenal répressif » pour punir les manquements en matière de levée d'hommes, fait main basse sur le Trésor public, soutient financièrement la production boulangère. Quelques jours de plus et, sous la menace de la famine et de l'inflation, elle eût été contrainte pour survivre de recourir à une économie totalement dirigée... « La force des choses nous conduit peut-être à des résultats auxquels nous n'avons point pensé [... ]»? 